\title{
(๑) International multicenter cohort study of pediatric brain arteriovenous malformations. Part 1: Predictors of hemorrhagic presentation
}

\author{
Dale Ding, MD, ${ }^{1}$ Robert M. Starke, MD, MSc, ${ }^{2}$ Hideyuki Kano, MD, PhD, ${ }^{3}$ David Mathieu, MD, ${ }^{4}$ \\ Paul P. Huang, MD, ${ }^{5}$ Caleb Feliciano, MD, ${ }^{6}$ Rafael Rodriguez-Mercado, MD, ${ }^{6}$ Luis Almodovar, MD, ${ }^{6}$ \\ Inga S. Grills, MD, ${ }^{7}$ Danilo Silva, MD, ${ }^{8}$ Mahmoud Abbassy, MD, ${ }^{8}$ Symeon Missios, MD, ${ }^{8}$ \\ Douglas Kondziolka, MD, ${ }^{5}$ Gene H. Barnett, MD, ${ }^{8}$ L. Dade Lunsford, MD, ${ }^{3}$ and \\ Jason P. Sheehan, MD, PhD' \\ ${ }^{1}$ University of Virginia, Department of Neurosurgery, Charlottesville, Virginia; ${ }^{2}$ University of Miami, Department of Neurological \\ Surgery, Miami, Florida; ${ }^{3}$ University of Pittsburgh, Department of Neurological Surgery, Pittsburgh, Pennsylvania; ${ }^{5}$ New York \\ University Langone Medical Center, Department of Neurosurgery, New York, New York; ${ }^{7 B}$ Beaumont Health System, Department \\ of Radiation Oncology, Royal Oak, Michigan; ${ }^{8}$ Cleveland Clinic Foundation, Department of Neurosurgery, Cleveland, Ohio; \\ ${ }^{4}$ University of Sherbrooke, Division of Neurosurgery, Sherbrooke, Quebec, Canada; and ${ }^{\circ}$ University of Puerto Rico, Section of \\ Neurological Surgery, San Juan, Puerto Rico
}

OBJECTIVE Brain arteriovenous malformations (AVMs) are the most common cause of spontaneous intracranial hemorrhage in pediatric patients (age < 18 years). Since the cumulative lifetime risk of AVM hemorrhage is considerable in children, an improved understanding of the risk factors influencing hemorrhagic presentation may aid in the management of pediatric AVMs. The aims of this first of a 2-part multicenter, retrospective cohort study are to evaluate the incidence and determine the predictors of hemorrhagic presentation in pediatric AVM patients.

METHODS The authors analyzed pooled AVM radiosurgery data from 7 institutions participating in the International Gamma Knife Research Foundation (IGKRF). Patients younger than 18 years at the time of radiosurgery and who had at least 12 months of follow-up were included in the study cohort. Patient and AVM characteristics were compared between unruptured and ruptured pediatric AVMs.

RESULTS A total of 357 pediatric patients were eligible for analysis, including 112 patients in the unruptured and 245 patients in the ruptured AVM cohorts ( $69 \%$ incidence of hemorrhagic presentation). The annual hemorrhage rate prior to radiosurgery was $6.3 \%$. Hemorrhagic presentation was significantly more common in deep locations (basal ganglia, thalamus, and brainstem) than in cortical locations (frontal, temporal, parietal, and occipital lobes) $(76 \%$ vs $62 \%, p=$ 0.006 ). Among the factors found to be significantly associated with hemorrhagic presentation in the multivariate logistic regression analysis, deep venous drainage $(\mathrm{OR} 3.2, p<0.001)$ was the strongest independent predictor, followed by female sex (OR 1.7, $p=0.042$ ) and smaller AVM volume (OR 1.1, $p<0.001)$.

CONCLUSIONS Unruptured and ruptured pediatric AVMs have significantly different patient and nidal features. Pediatric AVM patients who possess 1 or more of these high-risk features may be candidates for relatively more aggressive management strategies.

https://thejns.org/doi/abs/10.3171/2016.9.PEDS16283

KEY WORDS Gamma Knife; intracranial arteriovenous malformation; intracranial hemorrhages; pediatric; stereotactic radiosurgery; stroke; vascular malformations; vascular disorders 
B RAIN arteriovenous malformations (AVMs) are the most common cause of spontaneous intracranial hemorrhage (ICH) in the pediatric population (age $<18$ years), accounting for approximately $50 \%$ of pediatric hemorrhagic strokes. ${ }^{50} \mathrm{AVM}$ rupture in children leads to substantial neurological morbidity or mortality in many patients. ${ }^{47}$ Those who survive AVM hemorrhage can be left with neurocognitive or functional impairments, thus resulting in long-term quality-of-life and socioeconomic consequences for patients and their families. Compared with AVMs in adults, those in children may be more likely to present with $\mathrm{ICH} .{ }^{13}$

AVM hemorrhage can be prevented with prophylactic intervention for unruptured lesions. However, treatmentrelated morbidity can be significant, and, for some patients, the risk may exceed the risks associated with the natural history of conservatively managed unruptured AVMs. ${ }^{1,19,52,67}$ Although a general understanding of the risk factors that predispose an AVM to rupture has been proposed, those associated with hemorrhagic presentation in pediatric patients remain incompletely defined. ${ }^{44,49}$ Further evaluation of predictive factors for hemorrhagic presentation in pediatric AVM patients may help to guide the management of these lesions. Therefore, the aims of this first of a 2-part multicenter, retrospective cohort study are to 1) determine the incidence of hemorrhagic presentation in pediatric AVM patients, 2) compare the patient and AVM factors of unruptured versus ruptured pediatric AVMs, and 3) define the predictors of hemorrhagic presentation for the pediatric AVM population.

\section{Methods}

\section{Patient Selection for the Pediatric AVM Cohort}

We retrospectively evaluated databases of AVM patients who underwent treatment with Gamma Knife (Elekta AB) radiosurgery at 7 institutions participating in the International Gamma Knife Research Foundation (IGKRF). Institutional review board approval was obtained from each contributing center. The data extracted from each institution's database were de-identified and pooled by an independent third party. Data inconsistencies were directed to the contributing institution for clarification. The pooled data were then sent to the institution of the first and senior authors for analysis.

We intended for the study cohort to be uniform for both parts of the overall analysis. Therefore, the inclusion criteria for this Part 1 analysis were the same as those for Part 2, as follows: 1) patient age less than 18 years at the time of radiosurgery, 2) radiological and clinical follow-up of at least 12 months, and 3) sufficient baseline data regarding patient demographics, AVM features, and radiosurgery treatment parameters.

\section{Baseline Data and Variables}

Baseline data comprised patient and AVM variables. The angioarchitecture of each AVM was characterized by a combination of catheter cerebral angiography and thin-slice (slice width $\leq 1 \mathrm{~mm}$ ) MRI or CT (in patients for whom MRI was not feasible). Patient variables were sex, age, symptoms at the time of presentation, and time interval from clinical presentation to treatment with radiosurgery. AVM variables were prior hemorrhage status (dichotomized into unruptured vs ruptured), maximum nidus diameter, volume, eloquent location, deep venous drainage, and presence of AVM-associated intranidal or prenidal arterial aneurysms. Eloquent locations included sensorimotor, language, and visual cortex, hypothalamus and thalamus, internal capsule, brainstem, cerebellar peduncles, and deep cerebellar nuclei ${ }^{64}$ Cortical location included the frontal, temporal, parietal, and occipital lobes. Deep location included the basal ganglia, thalamus, and brainstem. The Spetzler-Martin grade, Virginia Radiosurgery AVM Scale (VRAS) score, and modified radiosurgery-based AVM score (RBAS) were determined for each AVM. ${ }^{64,69,71}$

\section{Statistical Analysis}

The annual pre-radiosurgery hemorrhage rate was calculated by dividing the total number of hemorrhages prior to radiosurgery by the total number of at-risk years. Using the assumption that AVMs are congenital lesions, the cumulative number of at-risk years is equivalent to the sum of the ages of all patients, who were included in the study cohort, at the time of radiosurgery.

Patients eligible for inclusion in the study cohort were dichotomized patients into unruptured (no prior AVM hemorrhage) and ruptured (prior AVM hemorrhage) pediatric AVM cohorts. Data are presented as mean and standard deviation for continuous variables and as frequency and percentage for categorical variables. Normality was assessed graphically and statistically. Continuous variables were compared using the unpaired, 2 independent-samples Student t-test or Wilcoxon rank-sum test, as appropriate. Categorical variables were compared using Pearson's chi-square or Fisher's exact test, as appropriate. Patient and AVM variables were assessed as covariates in a logistic regression analysis for predictors of hemorrhagic presentation (i.e., prior AVM hemorrhage). Covariates with $p<0.15$ in the univariate analysis were entered into a multivariate model. Spetzler-Martin grade, VRAS score, and RBAS were not included in the multivariate models, since components of these scales were analyzed. All statistical tests were 2 -sided. Statistical significance was defined as $\mathrm{p}<0.05$.

\section{Results}

\section{Unruptured and Ruptured Pediatric AVM Cohorts}

From a total of 2361 patients with at least 12 months of follow-up, 357 pediatric AVM patients were eligible for data analysis. The contribution from each of the 7 participating centers included 187 patients from the University of Virginia, 132 from the University of Pittsburgh, 14 from Cleveland Clinic, 12 from New York University, 6 from the University of Puerto Rico, 4 from Beaumont Health System, and 2 from the University of Sherbrooke.

A total of 281 hemorrhages occurred in 245 patients (68.6\%) prior to radiosurgery, including a single hemorrhage in each of 219 patients, 2 hemorrhages in each of 20 patients, 3 hemorrhages in each of 3 patients, 4 hemorrhages in each of 2 patients, and 5 hemorrhages in 1 pa- 
tient. If one assumes that AVMs are congenital lesions that are present from birth, the overall pediatric AVM cohort comprised a total of 4488 at-risk years, yielding an annual pre-radiosurgery hemorrhage rate of $6.3 \%$.

The ruptured pediatric AVM cohort comprised 245 patients with a history of prior AVM hemorrhage. If one assumes that ruptured AVMs were diagnosed at the first hemorrhage, a total of 36 recurrent hemorrhages occurred in 26 patients $(10.6 \%)$. The cumulative time interval between AVM diagnosis and radiosurgery in the ruptured AVM cohort was 243 years, which yielded an annual rehemorrhage rate of $14.8 \%$ prior to radiosurgery.

The unruptured pediatric AVM cohort comprised 112 patients without prior AVM hemorrhage. The most common presenting symptoms of these patients were focal neurological deficit in $47(42.0 \%)$, seizure in 29 (26.0\%), and headache in 19 (17.0\%). Eight patients were asymptomatic at the time of radiosurgery $(7.1 \%)$.

\section{Comparison of Unruptured and Ruptured Pediatric AVMs}

Table 1 compares the demographics and clinical characteristics of the unruptured and ruptured pediatric AVM cohorts. A significantly higher proportion of patients in the ruptured pediatric AVM cohort were female $(49.4 \%$ vs $37.5 \%, p=0.036$ ). A significantly higher proportion of ruptured pediatric AVMs were previously treated with resection $(8.6 \%$ vs $1.8 \%, \mathrm{p}=0.018)$ and fractionated external beam radiation therapy $(16.3 \%$ vs $6.3 \%, p=0.009)$, whereas a significantly lower proportion of ruptured AVMs underwent prior embolization (18.8\% vs $28.6 \%$; $\mathrm{p}=0.038$ ).

Table 2 describes the AVM angioarchitectural features of the 2 cohorts. Nidi in the ruptured pediatric AVM cohort were significantly smaller, based on maximum diameter (mean 2.1 vs $2.7 \mathrm{~cm}, \mathrm{p}=0.001$ ) and volume (mean 3.1 vs $\left.4.4 \mathrm{~cm}^{3}, \mathrm{p}<0.001\right)$. Deep venous drainage was significantly more common in ruptured AVMs $(73.5 \%$ vs $48.2 \%$, $\mathrm{p}<0.001)$. The ruptured AVM cohort had a significantly lower mean RBAS (mean 0.79 vs 0.93 , p $<0.001$ ), but it also had significantly higher VRAS scores $(\mathrm{p}<0.001)$.

TABLE 1. Comparison of demographics and clinical characteristics of the unruptured and ruptured pediatric AVM cohorts

\begin{tabular}{lccc}
\hline \multicolumn{1}{c}{ Factor } & $\begin{array}{c}\text { Unruptured AVM } \\
\text { Cohort }(n=112)\end{array}$ & $\begin{array}{c}\text { Ruptured AVM } \\
\text { Cohort }(n=245)\end{array}$ & $\begin{array}{c}p \\
\text { Value }\end{array}$ \\
\hline Male sex & $70(62.5 \%)$ & $124(50.6 \%)$ & $0.036^{*}$ \\
\hline $\begin{array}{l}\text { Age at radiosurgery, } \\
\text { mean (yrs) }\end{array}$ & $13.0 \pm 3.8$ & $12.4 \pm 3.6$ & 0.116 \\
\hline $\begin{array}{l}\text { Time interval from } \\
\text { presentation to radio- } \\
\text { surgery, mean (mos) }\end{array}$ & $11.1 \pm 28.6$ & $11.9 \pm 22.7$ & 0.837 \\
\hline Prior embolization & $32(28.6 \%)$ & $46(18.8 \%)$ & $0.038^{*}$ \\
\hline Prior resection & $2(1.8 \%)$ & $21(8.6 \%)$ & $0.018^{*}$ \\
\hline Prior EBRT & $7(6.3 \%)$ & $40(16.3 \%)$ & $0.009^{*}$ \\
\hline
\end{tabular}

EBRT = fractionated external beam radiation therapy.

Data are presented as numbers of patients (\%) unless otherwise indicated.

Means are presented with standard deviations.

* Statistically significant $(p<0.05)$.
TABLE 2. Comparison of AVM angioarchitectural features of the unruptured and ruptured pediatric AVM cohorts

\begin{tabular}{lccc}
\hline \multicolumn{1}{c}{ Factor } & $\begin{array}{c}\text { Unruptured AVM } \\
\text { Cohort }(\mathrm{n}=112)\end{array}$ & $\begin{array}{c}\text { Ruptured AVM } \\
\text { Cohort }(\mathrm{n}=245)\end{array}$ & $\mathrm{p}$ Value \\
\hline Diameter, mean $(\mathrm{cm})$ & $2.7 \pm 2.3$ & $2.1 \pm 0.9$ & $0.001^{*}$ \\
\hline Volume, mean $\left(\mathrm{cm}^{3}\right)$ & $4.4 \pm 3.8$ & $3.1 \pm 3.0$ & $<0.001^{*}$ \\
\hline Eloquent location & $87(77.7 \%)$ & $189(77.1 \%)$ & 0.911 \\
\hline Deep venous drainage & $54(48.2 \%)$ & $180(73.5 \%)$ & $<0.001^{*}$ \\
\hline Associated aneu- & $8(7.1 \%)$ & $19(7.8 \%)$ & 0.839 \\
rysms & & & \\
\hline Spetzler-Martin grade & & & 0.061 \\
\hline I & $7(6.3 \%)$ & $16(6.5 \%)$ & \\
\hline II & $49(43.8 \%)$ & $75(30.6 \%)$ & \\
\hline III & $43(38.4 \%)$ & $124(50.6 \%)$ & \\
\hline IV & $12(10.7 \%)$ & $30(12.2 \%)$ & \\
\hline V & $1(0.9 \%)$ & 0 & \\
\hline RBAS, mean & $0.93 \pm 0.42$ & $0.79 \pm 0.35$ & $<0.001^{*}$ \\
\hline VRAS score & & & $<0.001^{*}$ \\
\hline 0 & $7(6.3 \%)$ & 0 & \\
\hline 1 & $32(28.6 \%)$ & $31(12.7 \%)$ & \\
\hline 2 & $38(33.9 \%)$ & $93(38.0 \%)$ & \\
\hline 3 & $35(31.3 \%)$ & $68(27.8 \%)$ & \\
\hline 4 & 0 & $53(21.6 \%)$ & \\
\hline & & & \\
\hline
\end{tabular}

Data are presented as numbers of patients (\%) unless otherwise indicated.

Means are presented with standard deviations.

* Statistically significant $(p<0.05)$.

$\dagger$ Associated aneurysms include intranidal or prenidal aneurysms.

Table 3 details the AVM locations of 2 cohorts. A significantly higher proportion of unruptured pediatric AVMs were in a cortical location $(67.0 \%$ vs $49.0 \%$, p = $0.002)$ and located in the parietal lobe $(24.1 \%$ vs $9.8 \%$, p $<0.001$ ), whereas a significantly higher proportion of ruptured pediatric AVMs were in a deep location $(41.2 \%$ vs $28.6 \%, \mathrm{p}=0.022)$ and located in the basal ganglia $(14.7 \%$ vs $6.3 \%, \mathrm{p}=0.023)$ and corpus callosum $(4.9 \%$ vs $0, \mathrm{p}=$ $0.017)$.

When stratified by AVM location (Fig. 1), the rate of hemorrhagic presentation was significantly higher for deep-seated $(75.9 \%, 101 / 133$ patients) compared with cortically based nidi $(61.5 \%, 120 / 195$ patients; $\mathrm{p}=0.006)$. The AVM locations with the highest rates of hemorrhagic presentation were the corpus callosum $(100 \%, 12 / 12$ patients), basal ganglia $(83.7 \%, 36 / 43$ patients), and thalamus (77.8\%, $42 / 54$ patients). The AVM locations with the lowest rates of hemorrhagic presentation were the parietal lobe $(47.1 \%$, 24/51 patients), insula $(60.0 \%, 3 / 5$ patients), and frontal lobe $(61.8 \%, 34 / 55$ patients).

\section{Predictors of Hemorrhagic Presentation in Pediatric AVM Patients}

Table 4 details the univariate and multivariate logistic regression analyses for predictors of hemorrhagic presentation in pediatric AVM patients. Female sex $(\mathrm{p}=0.037)$, smaller AVM maximum diameter $(p=0.002)$ and volume $(p=0.001)$, deep venous drainage $(p<0.001)$, lower RBAS $(\mathrm{p}=0.001)$, and higher VRAS score $(\mathrm{p}<0.001)$ were sig- 
TABLE 3. Comparison of AVM locations in the unruptured and ruptured pediatric AVM cohorts

\begin{tabular}{lccc}
\hline \multicolumn{1}{c}{ AVM Location } & $\begin{array}{c}\text { Unruptured AVM } \\
\text { Cohort }(\mathrm{n}=112)\end{array}$ & $\begin{array}{c}\text { Ruptured AVM } \\
\text { Cohort }(\mathrm{n}=245)\end{array}$ & $\begin{array}{c}\mathrm{p} \\
\text { Value }\end{array}$ \\
\hline Frontal & $21(18.8 \%)$ & $34(13.9 \%)$ & 0.237 \\
\hline Temporal & $15(13.4 \%)$ & $28(11.4 \%)$ & 0.597 \\
\hline Parietal & $27(24.1 \%)$ & $24(9.8 \%)$ & $<0.001^{*}$ \\
\hline Occipital & $12(10.7 \%)$ & $34(13.9 \%)$ & 0.408 \\
\hline Basal ganglia & $7(6.3 \%)$ & $36(14.7 \%)$ & $0.023^{*}$ \\
\hline Thalamus & $12(10.7 \%)$ & $42(17.1 \%)$ & 0.116 \\
\hline Brainstem & $13(11.6 \%)$ & $23(9.4 \%)$ & 0.518 \\
\hline Cerebellum & $3(2.7 \%)$ & $9(3.7 \%)$ & 0.628 \\
\hline Corpus callosum & 0 & $12(4.9 \%)$ & $0.017^{*}$ \\
\hline Insula & $2(1.8 \%)$ & $3(1.2 \%)$ & 0.675 \\
\hline Cortical location $\dagger$ & $75(67.0 \%)$ & $120(49.0 \%)$ & $0.002^{*}$ \\
\hline Deep location $\neq$ & $32(28.6 \%)$ & $101(41.2 \%)$ & $0.022^{*}$ \\
\hline
\end{tabular}

Data are presented as numbers of patients (\%) unless otherwise indicated.

Means are presented with standard deviations.

* Statistically significant $(p<0.05)$.

$\dagger$ Frontal, temporal, parietal, or occipital.

$\ddagger$ Basal ganglia, thalamus, or brainstem.

nificantly associated with hemorrhagic presentation in the univariate analysis. In the multivariate analysis, the strongest independent predictor of hemorrhagic presentation was deep venous drainage (OR 3.2, 95\% CI 1.98-5.20; $\mathrm{p}<$ 0.001 ), followed by female sex (OR 1.7, 95\% CI 1.02-2.67; $\mathrm{p}=0.042)$ and smaller AVM volume (OR 1.1, 95\% CI 1.06-1.22; $\mathrm{p}<0.001)$.

\section{Discussion}

\section{AVMs as the Etiology of $\mathrm{ICH}$ in the Pediatric Population}

Although spontaneous intracranial hemorrhage (ICH) is rare in children, it accounts for a substantially greater proportion of stroke in the pediatric population, up to $50 \%$, compared with the adult population.,35,36 Analysis of pediatric stroke in the Greater Cincinnati metropolitan area over a 2-year span found an incidence of 1.2 per 100,000 for cerebral infarction and 1.5 per 100,000 for subarachnoid or intracerebral hemorrhage. ${ }^{3}$ The combined 30-day mortality for subarachnoid and intracerebral hemorrhage was $22 \%$. Analysis of a hospital discharge database in California over a 10-year period found an annual incidence of pediatric stroke of 2.3 per 100,000 , including 1.2 per 100,000 for ischemic and 1.1 per 100,000 for hemorrhagic stroke. ${ }^{35}$ Males had significantly higher rates of all stroke types, including subarachnoid (relative risk 1.24, 95\% CI 1.00-1.53; $\mathrm{p}=0.047$ ) and intracerebral (relative risk $1.34,95 \%$ CI 1.16-1.56; $\mathrm{p}=0.0001$ ) hemorrhage. Although the case-fatality rate was higher for boys suffering an ischemic stroke, the case-fatality rates for subarachnoid and intracerebral hemorrhage were similar between boys and girls. ${ }^{35}$

While ICH in adults is infrequently caused by AVM rupture, AVMs are the most common cause of $\mathrm{ICH}$ in the pediatric population (age < 18 years)..$^{13,50,51}$ Analysis of a prospective cohort of 23,877 patients younger than 16 years old and followed for 9 years found a 13 per 100,000 annual incidence of stroke, including 8 per 100,000 and 5 per 100,000 annual incidences of ischemic and hemorrhagic stroke, respectively. ${ }^{36}$ In $82 \%$ of the patients who suffered a hemorrhagic stroke, the cause was a vascular malformation. ${ }^{36}$ A study including 116 children with hemorrhagic stroke found an AVM to be the cause in $31 \%$ of cases. ${ }^{41}$ In a cohort of 34 patients with spontaneous $\mathrm{ICH}$, an AVM was identified as the cause in $47 \% .{ }^{50}$ The $\mathrm{ICH}$ mortality rate was $25 \%$, and $22 \%$ of survivors suffered from severe neurological deficits. ${ }^{50}$ Overall, AVMs contribute to a considerable degree of neurological morbidity and mortality secondary to stroke in the pediatric population.

\section{Natural History of Pediatric AVMs and Predictors of Hemorrhage}

Approximately $20 \%$ of AVMs are diagnosed during childhood or adolescence, and ICH accounts for approximately $50 \%-80 \%$ of clinical presentations in pediatric AVM patients. ${ }^{13,51}$ The incidence of hemorrhagic presentation was $69 \%$ in our multicenter pediatric AVM cohort, which is higher than in most adult AVM cohorts and comparable to rates previously reported for single-center pediatric AVM cohorts. Hetts et al. reported a significantly higher rate of hemorrhagic presentation in pediatric AVM patients than in adult AVM patients $(59 \%$ vs $41 \%$, p < 0.001). ${ }^{39} \mathrm{Ma}$ et al. reported a $61 \%$ incidence of hemorrhagic presentation in a cohort of 108 pediatric AVMs. ${ }^{49}$ Similarly, Ellis et al. found a $63 \%$ incidence of hemorrhagic presentation in a cohort of 135 pediatric AVMs. ${ }^{34}$ Kellner et al. also reported a $63 \%$ incidence of hemorrhagic presentation in a cohort of 85 pediatric AVMs. ${ }^{44}$

In the current study, a significantly higher proportion of nidi in the ruptured AVM cohort were localized to a deep location (41\% vs $29 \%, \mathrm{p}=0.022$ ), whereas a significantly higher proportion of unruptured pediatric AVMs were in a cortical location (67\% vs $49 \%, \mathrm{p}=0.002)$. Additionally, deep venous drainage was the strongest independent predictor of hemorrhagic presentation (OR 3.2, p < 0.001). This finding is consistent with prior studies of pediatric AVMs showing a significant correlation between hemorrhagic presentation and deep-seated nidus location and deep venous drainage. ${ }^{34,39,44,49}$ Ellis et al. and Kellner et al. found exclusively deep venous drainage to be an independent predictor of hemorrhagic presentation in each of the respective multivariate analyses. ${ }^{34,44}$ Ellis et al. also found infratentorial location to be associated with hemorrhagic presentation. ${ }^{34} \mathrm{Ma}$ et al. specifically identified periventricular location to be an independent predictor of hemorrhagic presentation. ${ }^{49}$

Smaller AVM volume was found to be an independent predictor of hemorrhagic presentation $(\mathrm{p}<0.001)$. Spetzler et al. reported a significantly higher rate of hemorrhagic presentation in AVMs smaller than $3 \mathrm{~cm}$ in diameter compared with those larger than $6 \mathrm{~cm}$ in diameter $(82 \%$ vs $21 \%$, $\mathrm{p}<0.001) .{ }^{63}$ This finding was attributed to significantly higher feeding-artery pressures, as determined by intraoperative measurements, in smaller AVMs. Ellis et al. and Ma et al. similarly identified a significant relationship between smaller AVM size and hemorrhagic presenta- 


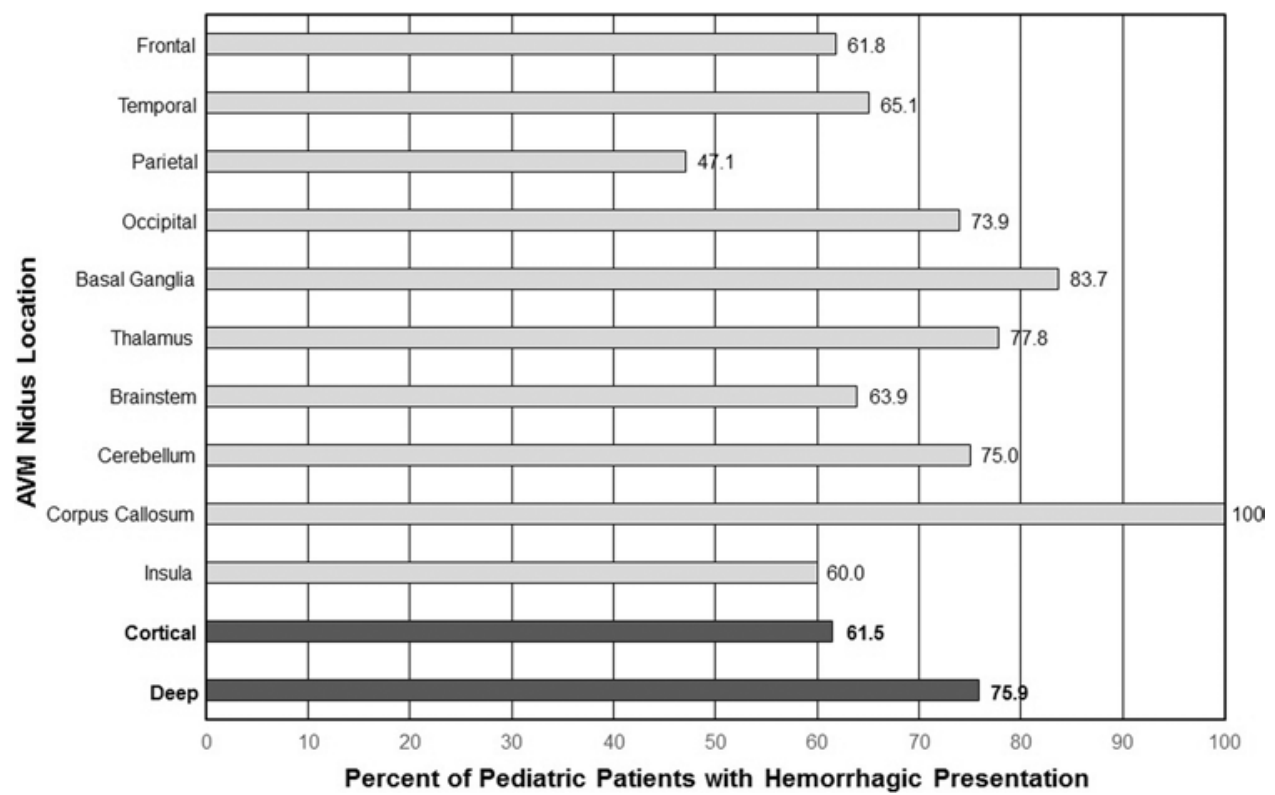

FIG. 1. Proportion of pediatric patients with hemorrhagic location, stratified by AVM nidus location. Cortical location includes the frontal, temporal, parietal, and occipital lobes. Deep location includes the basal ganglia, thalamus, and brainstem.

tion. ${ }^{34,49}$ Kellner et al. found that AVMs with hemorrhagic presentation were significantly more likely to have a single draining vein. ${ }^{44}$ This implies that small, compact nidi are more likely to present with hemorrhage than large or diffuse nidi with multiple venous outflow pathways. We also found female sex to be an independent predictor of hemorrhagic presentation $(\mathrm{p}=0.042)$, which has not been previously reported. This may suggest a biological distinction between AVMs in girls and those in boys, although further studies are necessary to test this hypothesis.

It is important to note that our study identifies predictors of hemorrhagic presentation, which are not necessarily the same factors that are predictive of a higher prospective hemorrhage risk in untreated AVMs. Deep venous drainage and deep AVM location have been shown to correlate with a higher AVM hemorrhage risk. ${ }^{58,65}$ However, factors such as smaller AVM size have been shown to cor- relate with a higher incidence of hemorrhagic presentation but have not been found to result in a significantly higher risk of AVM hemorrhage. ${ }^{38,58}$ Additionally, although pediatric AVMs may be more likely to present with $\mathrm{ICH}$, the risk of AVM hemorrhage has been shown to increase with age. ${ }^{46}$ Conversely, the presence of an associated arterial aneurysm has been found to increase an AVM's hemorrhage risk, but has not been consistently associated with hemorrhagic presentation in pediatric or adult AVM cohorts. ${ }^{5,38}$

\section{Implications of Hemorrhagic Presentation on the Management of Pediatric AVMs}

The specter of AVM hemorrhage is a major factor in the management of unruptured AVMs, due to the substantial and long-standing impact of clinical sequelae following AVM rupture. ${ }^{8}$ Pediatric AVM patients are exposed to a

TABLE 4. Univariate and multivariate logistic regression analyses for predictors of hemorrhagic presentation in pediatric AVM patients

\begin{tabular}{|c|c|c|c|c|c|c|}
\hline \multirow[b]{2}{*}{ Factor } & \multicolumn{3}{|c|}{ Univariate } & \multicolumn{3}{|c|}{ Multivariate } \\
\hline & OR & $95 \% \mathrm{Cl}$ & $p$ Value & OR & $95 \% \mathrm{Cl}$ & p Value \\
\hline Female sex & 1.63 & $1.03-2.57$ & $0.037^{*}$ & 1.65 & $1.02-2.67$ & 0.042 \\
\hline Younger age & 1.05 & $0.99-1.12$ & 0.116 & - & - & NS \\
\hline Smaller AVM max diameter & 1.48 & $1.16-1.89$ & $0.002^{*}$ & & & \\
\hline Smaller AVM volume & 1.12 & $1.05-1.20$ & $0.001^{*}$ & 1.14 & $1.06-1.22$ & $<0.001$ \\
\hline Deep venous drainage & 2.97 & $1.87-4.74$ & $<0.001^{*}$ & 3.21 & $1.98-5.20$ & $<0.001$ \\
\hline Higher Spetzler-Martin grade & 1.22 & $0.92-1.63$ & 0.167 & $-\dagger$ & $-\dagger$ & $-\dagger$ \\
\hline Lower RBAS & 2.77 & $1.52-5.07$ & $0.001^{*}$ & $-\dagger$ & $-\dagger$ & $-\dagger$ \\
\hline Higher VRAS score & 2.11 & $1.63-2.74$ & $<0.001^{*}$ & $-\dagger$ & $-\dagger$ & $-\dagger$ \\
\hline
\end{tabular}

NS = not significant in the multivariate analysis $(p \geq 0.05)$.

Only factors with $p<0.15$ in the univariate analysis are listed. Boldface type indicates statistical significance in the multivariate analysis.

* Statistically significant in the univariate analysis $(p<0.05)$.

$\dagger$ Grading scales were not included in the multivariate analysis. 
particularly elevated cumulative risk of hemorrhage during their lifetimes. ${ }^{48}$ Therefore, the impetus for AVM intervention in children and adolescents may be greater than in adults, especially for ruptured lesions, which are known to have an increased hemorrhage risk compared with unruptured ones. ${ }^{38,46,58,65}$ In general, the majority of ruptured AVMs undergo intervention, although the treatment modality and approach can vary widely based on physicianand institution-specific experiences and preferences. $26,45,62,70$

The benefit of intervention for unruptured nidi is more controversial, particularly given the scarcity of data comparing the natural history and treatment outcomes for unruptured AVMs in pediatric patients. ${ }^{1,52,67}$ Our findings suggest that smaller, deep-seated AVMs that are unruptured warrant consideration for treatment, given their propensity toward hemorrhagic presentation. Stereotactic radiosurgery is especially suited for the treatment of small-

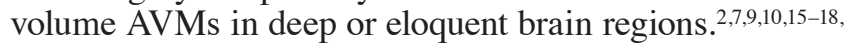
21-25,27-33,42,43,53,55,56,59,61,66,68,72 However, advances in endovascular and microsurgical technology and techniques have improved the feasibility of embolization, resection, and multimodality therapy for deep-seated, high-grade, and complex AVMs. ${ }^{6,11,14,40,60}$

AVM angioarchitecture is not static and changes over time as children grow and develop into adults. ${ }^{20,54}$ Hetts et al. compared the angioarchitecture of 203 pediatric to 630 adult AVMs and found that AVM-associated arterial aneurysms and venous ectasia were significantly more common in adult AVMs than in those in children. ${ }^{39}$ Therefore, the development of high-risk features may prompt intervention in a patient with a conservatively managed AVM. Hetts et al. reported a significantly higher incidence of exclusively deep venous drainage in ruptured pediatric compared with adult AVMs, which may contribute to the higher incidence of hemorrhagic presentation in pediatric AVMs. ${ }^{39}$

\section{Study Limitations}

Despite the large number of pediatric patients accrued from multiple institutions, this study remains limited by its retrospective design. Because all of the patients in the overall study cohort were selected for and underwent intervention with radiosurgery, the composition of this cohort may not be representative of pediatric AVM patients in general. Therefore, it is important to emphasize that this is not a natural history study. Specifically, patients who presented with large-volume AVM hemorrhages may have undergone urgent surgical hematoma evacuation and AVM resection, which may bias our results toward a lower incidence of hemorrhagic presentation. In contrast, patients with low-grade unruptured AVMs may have been treated surgically and those with high-grade unruptured AVMs may have been managed conservatively, which could bias our results toward a higher incidence of hemorrhagic presentation, given that these lesions tend to present with seizures. ${ }^{21}$ Due to the selection bias of this study, symptomatic patients were likely over-represented compared with asymptomatic ones. Additionally, since hemorrhage is the most common clinical manifestation of an AVM, our cohort likely contains a higher proportion of patients with hemorrhagic presentation than an unselected cohort of pediatric AVM patients.
The reasons for referral for radiosurgery, and the decision algorithms regarding the use of resection, embolization, and radiosurgery were not standardized across the different centers participating in this study. We acknowledge that this could lead to the inclusion of some AVMs, particularly small-volume, noneloquent AVMs, which may otherwise be managed by resection under divergent treatment practices. Since each contributing institution is a tertiary referral center for AVM radiosurgery, complete clinical information was unavailable in all cases. Therefore, the severity and functional impact of neurological morbidity secondary to AVM hemorrhage was unknown for some patients. Hemorrhages resulting in death or substantial disability that patients did not recover from sufficiently to be suitable candidates for radiosurgery were excluded from the study cohort. Additionally, data regarding patients with less than 12 months of follow-up were not provided by the contributing institutions. Therefore, the rates of AVM hemorrhage-related morbidity and mortality prior to radiosurgery could not be determined.

Our estimated annual hemorrhage risk of $6.3 \%$ prior to radiosurgery is considerably higher than the annual hemorrhage risk reported in AVM natural history studies. $5,12,37,38,46,57$ Since our study cohort is biased toward the inclusion of ruptured AVMs, the calculated pre-radiosurgery hemorrhage risk is artificially elevated and, therefore, should not be interpreted as a representation of the natural history of all untreated pediatric AVMs. However, the hemorrhage risk of an untreated AVM can vary significantly, depending on whether there is a history of prior rupture as well as on nidus location and angioarchitecture $^{58,65}$ Furthermore, an AVM's hemorrhage risk is not a static figure, as it has been shown to change over the course of a patient's lifetime. ${ }^{46}$ One should also consider that AVM hemorrhages may exhibit a pattern of temporal clustering. Therefore, the estimated annual pre-radiosurgery hemorrhage risk should be interpreted with caution, since our study was not designed to evaluate this aspect of pediatric AVMs.

The limitations on our calculation of the annual hemorrhage risk prior to radiosurgery also affect our analysis of risk factors for hemorrhagic presentation. Based on natural history studies of untreated AVMs, we believe it is reasonable to postulate that untreated, small-volume AVMs are less likely to present with symptoms other than hemorrhage, rather than being more likely to present with hemorrhage. ${ }^{46}$ In contrast, untreated AVMs with deep venous drainage are likely predisposed to hemorrhage, rather than being less likely to present with other symptoms. However, an AVM's natural history and its mode of clinical presentation are intricately entwined, and therefore, careful consideration of both aspects are necessary for the management of these patients.

\section{Conclusions}

Significant differences in patient demographics and nidal angioarchitectural features exist between unruptured and ruptured AVMs in pediatric patients who underwent stereotactic radiosurgery. Female sex, smaller nidus size, and the presence of deep venous drainage predispose pedi- 
atric AVM patients to hemorrhagic presentation. Since the cumulative lifetime hemorrhage risk for a child harboring an AVM is substantial, factors influencing hemorrhagic presentation should be considered in the management of these patients. Specifically, a more aggressive posture toward intervention may be taken for children with unruptured AVMs who are particularly prone to eventual hemorrhage. However, the findings from this study may not be generalizable to all pediatric AVM patients, and effects of selection and referral bias on our cohort should not be underestimated. Additional prospective data from natural history studies are necessary to strengthen the recommendations regarding intervention or conservative management of pediatric AVMs.

\section{Acknowledgments}

We appreciate the assistance of Ms. Linda Baxendell with the coordination of data for the International Gamma Knife Research Consortium.

\section{References}

1. Al-Shahi Salman R, White PM, Counsell CE, du Plessis J, van Beijnum J, Josephson CB, et al: Outcome after conservative management or intervention for unruptured brain arteriovenous malformations. JAMA 311:1661-1669, 2014

2. Awad AJ, Walcott BP, Stapleton CJ, Ding D, Lee CC, Loeffler JS: Repeat radiosurgery for cerebral arteriovenous malformations. J Clin Neurosci 22:945-950, 2015

3. Broderick J, Talbot GT, Prenger E, Leach A, Brott T: Stroke in children within a major metropolitan area: the surprising importance of intracerebral hemorrhage. J Child Neurol 8:250-255, 1993

4. Brown RD Jr, Wiebers DO, Forbes GS: Unruptured intracranial aneurysms and arteriovenous malformations: frequency of intracranial hemorrhage and relationship of lesions. J Neurosurg 73:859-863, 1990

5. Brown RD Jr, Wiebers DO, Forbes G, O'Fallon WM, Piepgras DG, Marsh WR, et al: The natural history of unruptured intracranial arteriovenous malformations. J Neurosurg 68:352-357, 1988

6. Buell TJ, Ding D, Starke RM, Webster Crowley R, Liu KC: Embolization-induced angiogenesis in cerebral arteriovenous malformations. J Clin Neurosci 21:1866-1871, 2014

7. Chen CJ, Chivukula S, Ding D, Starke RM, Lee CC, Yen CP, et al: Seizure outcomes following radiosurgery for cerebral arteriovenous malformations. Neurosurg Focus 37(3):E17, 2014

8. Choi JH, Mast H, Sciacca RR, Hartmann A, Khaw AV, Mohr JP, et al: Clinical outcome after first and recurrent hemorrhage in patients with untreated brain arteriovenous malformation. Stroke 37:1243-1247, 2006

9. Cohen-Inbar O, Ding D, Chen CJ, Sheehan JP: Stereotactic radiosurgery for deep intracranial arteriovenous malformations, part 1: brainstem arteriovenous malformations. J Clin Neurosci 24:30-36, 2016

10. Cohen-Inbar O, Ding D, Sheehan JP: Stereotactic radiosurgery for deep intracranial arteriovenous malformations, part 2: basal ganglia and thalamus arteriovenous malformations. J Clin Neurosci 24:37-42, 2016

11. Consoli A, Renieri L, Nappini S, Limbucci N, Mangiafico S: Endovascular treatment of deep hemorrhagic brain arteriovenous malformations with transvenous onyx embolization. AJNR Am J Neuroradiol 34:1805-1811, 2013

12. Crawford PM, West CR, Chadwick DW, Shaw MD: Arteriovenous malformations of the brain: natural history in unoperated patients. J Neurol Neurosurg Psychiatry 49:1-10, 1986
13. Di Rocco C, Tamburrini G, Rollo M: Cerebral arteriovenous malformations in children. Acta Neurochir (Wien) 142:145158,2000

14. Ding D, Liu KC: Predictive capability of the Spetzler-Martin versus supplementary grading scale for microsurgical outcomes of cerebellar arteriovenous malformations. J Cerebrovasc Endovasc Neurosurg 15:307-310, 2013

15. Ding D, Quigg M, Starke RM, Xu Z, Yen CP, Przybylowski CJ, et al: Radiosurgery for temporal lobe arteriovenous malformations: effect of temporal location on seizure outcomes. J Neurosurg 123:924-934, 2015

16. Ding D, Quigg M, Starke RM, Yen CP, Przybylowski CJ, Dodson BK, et al: Cerebral arteriovenous malformations and epilepsy, part 2: predictors of seizure outcomes following radiosurgery. World Neurosurg 84:653-662, 2015

17. Ding D, Sheehan JP, Starke RM, Durst CR, Raper DM, Conger JR, et al: Embolization of cerebral arteriovenous malformations with silk suture particles prior to stereotactic radiosurgery. J Clin Neurosci 22:1643-1649, 2015

18. Ding D, Starke RM, Kano H, Lee JY, Mathieu D, Pierce J, et al: Stereotactic radiosurgery for Spetzler-Martin Grade III arteriovenous malformations: an international multicenter study. J Neurosurg [epub ahead of print April 15, 2016. DOI: 10.3171/2016.1.JNS152564]

19. Ding D, Starke RM, Kano H, Mathieu D, Huang P, Kondziolka D, et al: Radiosurgery for cerebral arteriovenous malformations in a randomized trial of unruptured brain arteriovenous malformations (ARUBA)-eligible patients: a multicenter study. Stroke 47:342-349, 2016

20. Ding D, Starke RM, Liu KC, Crowley RW: Cortical plasticity in patients with cerebral arteriovenous malformations. J Clin Neurosci 22:1857-1861, 2015

21. Ding D, Starke RM, Quigg M, Yen CP, Przybylowski CJ, Dodson BK, et al: Cerebral arteriovenous malformations and epilepsy, part 1: predictors of seizure presentation. World Neurosurg 84:645-652, 2015

22. Ding D, Starke RM, Yen CP, Sheehan JP: Radiosurgery for cerebellar arteriovenous malformations: does infratentorial location affect outcome? World Neurosurg 82:e209-e217, 2014

23. Ding D, Xu Z, Shih HH, Starke RM, Yen CP, Sheehan JP: Stereotactic radiosurgery for partially resected cerebral arteriovenous malformations. World Neurosurg 85:263-272, 2016

24. Ding D, Xu Z, Starke RM, Yen CP, Shih HH, Buell TJ, et al: Radiosurgery for cerebral arteriovenous malformations with associated arterial aneurysms. World Neurosurg 87:77-90, 2016

25. Ding D, Xu Z, Yen CP, Starke RM, Sheehan JP: Radiosurgery for cerebral arteriovenous malformations in elderly patients: effect of advanced age on outcomes after intervention. World Neurosurg 84:795-804, 2015

26. Ding D, Xu Z, Yen CP, Starke RM, Sheehan JP: Radiosurgery for unruptured cerebral arteriovenous malformations in pediatric patients. Acta Neurochir (Wien) 157:281-291, 2015

27. Ding D, Yen CP, Starke RM, Xu Z, Sheehan JP: Effect of prior hemorrhage on intracranial arteriovenous malformation radiosurgery outcomes. Cerebrovasc Dis 39:53-62, 2015

28. Ding D, Yen CP, Starke RM, Xu Z, Sheehan JP: Radiosurgery for ruptured intracranial arteriovenous malformations. J Neurosurg 121:470-481, 2014

29. Ding D, Yen CP, Starke RM, Xu Z, Sun X, Sheehan JP: Outcomes following single-session radiosurgery for high-grade intracranial arteriovenous malformations. Br J Neurosurg 28:666-674, 2014

30. Ding D, Yen CP, Starke RM, Xu Z, Sun X, Sheehan JP: Radiosurgery for Spetzler-Martin Grade III arteriovenous malformations. J Neurosurg 120:959-969, 2014 
31. Ding D, Yen CP, Xu Z, Starke RM, Sheehan JP: Radiosurgery for low-grade intracranial arteriovenous malformations. J Neurosurg 121:457-467, 2014

32. Ding D, Yen CP, Xu Z, Starke RM, Sheehan JP: Radiosurgery for patients with unruptured intracranial arteriovenous malformations. J Neurosurg 118:958-966, 2013

33. Ding D, Yen CP, Xu Z, Starke RM, Sheehan JP: Radiosurgery for primary motor and sensory cortex arteriovenous malformations: outcomes and the effect of eloquent location. Neurosurgery 73:816-824, 2013

34. Ellis MJ, Armstrong D, Vachhrajani S, Kulkarni AV, Dirks PB, Drake JM, et al: Angioarchitectural features associated with hemorrhagic presentation in pediatric cerebral arteriovenous malformations. J Neurointerv Surg 5:191-195, 2013

35. Fullerton HJ, Wu YW, Zhao S, Johnston SC: Risk of stroke in children: ethnic and gender disparities. Neurology 61:189194,2003

36. Giroud M, Lemesle M, Gouyon JB, Nivelon JL, Milan C, Dumas R: Cerebrovascular disease in children under 16 years of age in the city of Dijon, France: a study of incidence and clinical features from 1985 to 1993 . J Clin Epidemiol 48:1343-1348, 1995

37. Graf CJ, Perret GE, Torner JC: Bleeding from cerebral arteriovenous malformations as part of their natural history. $\mathbf{J}$ Neurosurg 58:331-337, 1983

38. Gross BA, Du R: Natural history of cerebral arteriovenous malformations: a meta-analysis. J Neurosurg 118:437-443, 2013

39. Hetts SW, Cooke DL, Nelson J, Gupta N, Fullerton H, Amans MR, et al: Influence of patient age on angioarchitecture of brain arteriovenous malformations. AJNR Am J Neuroradiol 35:1376-1380, 2014

40. Iosif C, Mendes GA, Saleme S, Ponomarjova S, Silveira EP, Caire F, et al: Endovascular transvenous cure for ruptured brain arteriovenous malformations in complex cases with high Spetzler-Martin grades. J Neurosurg 122:1229-1238, 2015

41. Jordan LC, Johnston SC, Wu YW, Sidney S, Fullerton HJ: The importance of cerebral aneurysms in childhood hemorrhagic stroke: a population-based study. Stroke 40:400-405, 2009

42. Kano H, Flickinger JC, Yang HC, Flannery TJ, Tonetti D, Niranjan A, et al: Stereotactic radiosurgery for SpetzlerMartin Grade III arteriovenous malformations. J Neurosurg 120:973-981, 2014

43. Kano H, Kondziolka D, Flickinger JC, Yang HC, Flannery TJ, Awan NR, et al: Stereotactic radiosurgery for arteriovenous malformations, part 2: management of pediatric patients. J Neurosurg Pediatr 9:1-10, 2012

44. Kellner CP, McDowell MM, Phan MQ, Connolly ES, Lavine SD, Meyers PM, et al: Number and location of draining veins in pediatric arteriovenous malformations: association with hemorrhage. J Neurosurg Pediatr 14:538-545, 2014

45. Kim H, Abla AA, Nelson J, McCulloch CE, Bervini D, Morgan MK, et al: Validation of the supplemented Spetzler-Martin grading system for brain arteriovenous malformations in a multicenter cohort of 1009 surgical patients. Neurosurgery 76:25-33, 2015

46. Kim H, Al-Shahi Salman R, McCulloch CE, Stapf C, Young WL: Untreated brain arteriovenous malformation: patientlevel meta-analysis of hemorrhage predictors. Neurology 83:590-597, 2014

47. Kondziolka D, Humphreys RP, Hoffman HJ, Hendrick EB, Drake JM: Arteriovenous malformations of the brain in children: a forty year experience. Can J Neurol Sci 19:40-45, 1992

48. Kondziolka D, McLaughlin MR, Kestle JR: Simple risk predictions for arteriovenous malformation hemorrhage. Neurosurgery 37:851-855, 1995
49. Ma L, Huang Z, Chen XL, Ma J, Liu XJ, Wang H, et al: Periventricular location as a risk factor for hemorrhage and severe clinical presentation in pediatric patients with untreated brain arteriovenous malformations. AJNR Am J Neuroradiol 36:1550-1557, 2015

50. Meyer-Heim AD, Boltshauser E: Spontaneous intracranial haemorrhage in children: aetiology, presentation and outcome. Brain Dev 25:416-421, 2003

51. Millar C, Bissonnette B, Humphreys RP: Cerebral arteriovenous malformations in children. Can J Anaesth 41:321-331, 1994

52. Mohr JP, Parides MK, Stapf C, Moquete E, Moy CS, Overbey JR, et al: Medical management with or without interventional therapy for unruptured brain arteriovenous malformations (ARUBA): a multicentre, non-blinded, randomised trial. Lancet 383:614-621, 2014

53. Moosa S, Chen CJ, Ding D, Lee CC, Chivukula S, Starke $\mathrm{RM}$, et al: Volume-staged versus dose-staged radiosurgery outcomes for large intracranial arteriovenous malformations. Neurosurg Focus 37(3):E18, 2014

54. Mouchtouris N, Jabbour PM, Starke RM, Hasan DM, Zanaty M, Theofanis T, et al: Biology of cerebral arteriovenous malformations with a focus on inflammation. J Cereb Blood Flow Metab 35:167-175, 2015

55. Oermann EK, Ding D, Yen CP, Starke RM, Bederson JB, Kondziolka D, et al: Effect of prior embolization on cerebral arteriovenous malformation radiosurgery outcomes: a casecontrol study. Neurosurgery 77:406-417, 2015

56. Oermann EK, Rubinsteyn A, Ding D, Mascitelli J, Starke $\mathrm{RM}$, Bederson JB, et al: Using a machine learning approach to predict outcomes after radiosurgery for cerebral arteriovenous malformations. Sci Rep 6:21161, 2016

57. Ondra SL, Troupp H, George ED, Schwab K: The natural history of symptomatic arteriovenous malformations of the brain: a 24-year follow-up assessment. J Neurosurg 73:387391,1990

58. Pollock BE, Flickinger JC, Lunsford LD, Bissonette DJ, Kondziolka D: Factors that predict the bleeding risk of cerebral arteriovenous malformations. Stroke 27:1-6, 1996

59. Pollock BE, Flickinger JC, Lunsford LD, Maitz A, Kondziolka D: Factors associated with successful arteriovenous malformation radiosurgery. Neurosurgery 42:1239-1247, 1998

60. Potts MB, Young WL, Lawton MT: Deep arteriovenous malformations in the basal ganglia, thalamus, and insula: microsurgical management, techniques, and results. Neurosurgery 73:417-429, 2013

61. Przybylowski CJ, Ding D, Starke RM, Yen CP, Quigg M, Dodson B, et al: Seizure and anticonvulsant outcomes following stereotactic radiosurgery for intracranial arteriovenous malformations. J Neurosurg 122:1299-1305, 2015

62. Saatci I, Geyik S, Yavuz K, Cekirge HS: Endovascular treatment of brain arteriovenous malformations with prolonged intranidal Onyx injection technique: long-term results in 350 consecutive patients with completed endovascular treatment course. J Neurosurg 115:78-88, 2011

63. Spetzler RF, Hargraves RW, McCormick PW, Zabramski JM, Flom RA, Zimmerman RS: Relationship of perfusion pressure and size to risk of hemorrhage from arteriovenous malformations. J Neurosurg 76:918-923, 1992

64. Spetzler RF, Martin NA: A proposed grading system for arteriovenous malformations. J Neurosurg 65:476-483, 1986

65. Stapf C, Mast H, Sciacca RR, Choi JH, Khaw AV, Connolly ES, et al: Predictors of hemorrhage in patients with untreated brain arteriovenous malformation. Neurology 66:1350-1355, 2006

66. Starke RM, Kano H, Ding D, Lee JY, Mathieu D, Whitesell $\mathrm{J}$, et al: Stereotactic radiosurgery for cerebral arteriovenous malformations: evaluation of long-term outcomes in a mul- 
ticenter cohort. J Neurosurg [epub ahead of print March 4, 2016. DOI: 10.3171/2015.9.JNS151311]

67. Starke RM, Sheehan JP, Ding D, Liu KC, Kondziolka D, Crowley RW, et al: Conservative management or intervention for unruptured brain arteriovenous malformations. World Neurosurg 82:e668-e669, 2014

68. Starke RM, Yen CP, Chen CJ, Ding D, Mohila CA, Jensen $\mathrm{ME}$, et al: An updated assessment of the risk of radiationinduced neoplasia after radiosurgery of arteriovenous malformations. World Neurosurg 82:395-401, 2014

69. Starke RM, Yen CP, Ding D, Sheehan JP: A practical grading scale for predicting outcome after radiosurgery for arteriovenous malformations: analysis of 1012 treated patients. J Neurosurg 119:981-987, 2013

70. Walcott BP, Hattangadi-Gluth JA, Stapleton CJ, Ogilvy CS, Chapman PH, Loeffler JS: Proton beam stereotactic radiosurgery for pediatric cerebral arteriovenous malformations. Neurosurgery 74:367-374, 2014

71. Wegner RE, Oysul K, Pollock BE, Sirin S, Kondziolka D, Niranjan A, et al: A modified radiosurgery-based arteriovenous malformation grading scale and its correlation with outcomes. Int J Radiat Oncol Biol Phys 79:1147-1150, 2011

72. Yen CP, Ding D, Cheng CH, Starke RM, Shaffrey M, Sheehan J: Gamma Knife surgery for incidental cerebral arteriovenous malformations. J Neurosurg 121:1015-1021, 2014

\section{Disclosures}

There was no financial support for this study. Dr. Grills reports being a stockholder in and serving on the Board of Directors of Greater Michigan Gamma Knife and holding a research grant from Elekta as the principal investigator of the Elekta Collaborative Lung Research Group (unrelated to this study). Dr. Kondziolka reports receiving nonmonetary (software) registry support from Elekta. Dr. Lunsford reports being a consultant for and stockholder in Elekta and a consultant for DSMB.

\section{Author Contributions}

Conception and design: Sheehan, Ding, Starke. Acquisition of data: Starke, Kano, Mathieu, Huang, Feliciano, Rodriguez-Mercado, Almodovar, Grills, Silva, Abbassy, Missios, Kondziolka, Barnett, Lunsford. Analysis and interpretation of data: Sheehan, Ding, Starke. Drafting the article: Sheehan, Ding. Critically revising the article: all authors. Reviewed submitted version of manuscript: all authors. Approved the final version of the manuscript on behalf of all authors: Sheehan. Statistical analysis: Starke. Study supervision: Sheehan.

\section{Supplemental Information Companion Papers}

Starke RM, Ding D, Kano H, Mathieu D, Huang PP, Feliciano $\mathrm{C}$, et al: International multicenter cohort study of pediatric brain arteriovenous malformations. Part 2: Outcomes after stereotactic radiosurgery. DOI: 10.3171/2016.9.PEDS16284.

\section{Correspondence}

Jason Sheehan, Department of Neurosurgery, University of Virginia, Box 800212, Charlottesville, VA 22908. email: jps2f@ virginia.edu. 